\title{
Yetişkin Bireylerde Narsisizm, Yakın İlişkiler ve Cinsellik ${ }^{1}$
}

\author{
DOI: 10.26466/opus.671715 \\ * \\ Berhu Erdoğan *- Muzaffer Şahin ** \\ *Klinik Psikolog, Nişantaşı Üniversitesi, İ̈BBF, İstanbul/Türkiye \\ E-Posta: berhu.erdogan@yahoo.com \\ ORCID: 0000-0002-0598-4331 \\ **Dr. Öğretim Üyesi, CIIP, İstanbul Arel Üniversitesi, FEF,İstanbul/Türkiye \\ E-Posta: muzsah@gmail.com \\ ORCID: $\underline{0000-0002-2411-2803}$
}

\section{Öz}

Bu çalışmada alan yazında sıklıkla karşılaşılan bir kavram olan narsisizmin yakın ilişkiler ve cinsel davranışlar üzerindeki etkisini incelemek amaçlanmıştır. Bu çalışma ile narsisizm konusundaki alan yazına katkı săglarken aynı zamanda elde edilen sonuçların klinik ve akademik alanda yapılan çalışmalarda yol gösterici olması amaçlanmıştır. Bu amaç doğrultusunda rastgele örneklem yöntemi ile seçilen 350 katılımcıya Beş Faktör Narsisizm Ölçeği, İlişki Doyum Ölçeği, Cinsel Risk Alma Ölçeği, Cinsel Tutum Ölçeği ve Cinsel Heyecan Arama Ölçekleri uygulanmıştır. Çalışmada katılımcıların düşünce ve davranışlarında bir değişiklik yapılmamış yalnızca var olan durumun tespit edilmesi hedeflenmiştir.

Elde edilen veriler SPSS 22 paket programı ile çözümlenerek araştırma sorularına uygun olacak biçimde $t$ testi ve pearson korelasyon analizi yapılmıştır. Yapılan analiz sonucunda ise narsisizmin alt boyutlarından kırllgan ve büyüklenmeci narsisizmin ilişki doyumu, cinsel tutum ve davranışlarla çeşitli düzeylerde ilişkili olduğu görülmüştür. Elde edilen bulgular literatür ışı̆̆ında incelenmiş ve çalışmanın sonucunda elde edilen bulguların literatürdeki kısıtlı sayıdaki çalışma ile örtüştü̆̈̈̈ görülmüştür. Çalışmaya ait sınırlılık ve öneriler ise metnin son kısmında belirtilmiştir.

Anahtar Kelimeler: narsisizm, ilişki doyumu, cinsellik

\footnotetext{
${ }^{1}$ Bu çalışma 2019 yılında Arel Üniversitesi SBE Klinik Psikoloji Y. L. Programından mezun olan Berhu Erdoğan'ın tezinden üretilmiştir.
} 


\title{
Narcissism, Close Relationships and Sexuality in Adult Individuals
}

\begin{abstract}
In this study, it is aimed to examine the effect of narcissism, which is a frequently encountered concept in the literature, on close relationships and sexual behaviors. While this study contributes to the literature on narcissism and also the results obtained in clinical studies in the academic field and are intended to be guiding. For this purpose randomly selected 350 participants with Narcissism Five Factor Inventory, Relationship Satisfaction Scale and Sexual Risk Taking Scale, Sexual Attitudes and Sexual Sensation Seeking Scale were applied. The study participants were no changes in thinking and behavior is intended only to identify the existing situation.

Then, the data obtained from the sample were analyzed with SPSS 22 package program. In the first phase of the analysis, the normality of data distribution was tested. Then, the research questions $t$ test and pearson correlation analysis were solved. As a result of the analyzes, it has been observed that vulanerable and grandiose narcissism, which is one of the sub-dimensions of narcissism, is associated with relationship satisfaction, sexual attitudes and behaviors at various levels. The findings were reviewed the literature and shown to overlap with the limited number of studies in the literature of the findings obtained as a result of the study. The limitations and suggestions of the study are stated in the last part of the text.
\end{abstract}

Keywords: narcissism, relationship satisfaction, sexuality 


\section{Giriş}

Narsisizm kavramı ile ilgili literatüre bakıldığında ağırlıklı olarak bu kavramın klinik görünümünün incelendiği görülmüştür. Narsisizmin tanımı ve tanı kriterlerine bakıldığında ise bu kavramın bireylerin sosyal ve ilişkisel yaşamları üzerinde etkili olmasının kaçınılmaz olacağı görülmektedir. Bu nedenle bu çalışmada temel olarak amaçlanan narsisizmin, yakın (romantik) ilişkiler üzerindeki etkisini incelemektir.

\section{Çalışmanın Kavramsal ve Kuramsal Çerçevesi}

Narsisizm kavramının tarihçesine bakıldığında bu kavramın mitolojik bir öykü olan Narkisos mitinden köken aldığı görülmektedir. Bu mite göre Narkisos'un olağanüstü güzelliği onu gören herkesi etki altında bırakıyormuş ve bir gün ona aşık olan birisi şöyle bir dilekte bulunmuş "O da sevsin ve sevdiğine hiç kavuşamasın." Bu dilek ise tanrılar tarafından kabul edilmiş. Bir gün Narkisos, su içmek için eğildiği bir gölde kendi yansımasının güzelliğine kapılarak imkânsız bir aşka düşmüş ve bu imkânsız aşk Narkisos'un sonunu getirmiştir. Narkisos, Nihayet öldüğünde bedeni bir çiçeğe dönüşmüş halde bulunmuştur (Anll, 2010; Campbell ve Miller, 2011; Morelli ve Couderc, 2011).

Bu kavramın ruh sağlığı alanında kullanımı ise Isıdor Sadger'e ait bir makalenin Sigmund Freud (1856-1939) tarafindan 1909 yılında Viyana Psikanaliz Topluluğuna ait bir toplantıda ele alınmasıyla gerçekleşmiştir (Kızıltan, 2004; Pulver, 1970). Freud, narsisizm kavramına ilk kez “Cinsellik Üzerine Üç Deneme" isimli metninde değinmiştir. Sonraki yıllarda yazmış olduğu "Narsisizm Üzerine" metninde ise konuyu detaylı biçimde ele almıştır (Erten, 2015).

\section{Narsisizm Kavramının Gelişimi}

Narsisizm kavramı Freud'un 1914 yılında yayınladığı "Narsisizm Üzerine" metninde detaylıca ele alınmıştır. Freud'a göre narsisizm bir sapkınlık/sapıklık değil insan gelişiminin doğal bir parçasıdır. Freud, gelişimsel süreçte "birincil ve ikincil narsisizm" olarak adlandırdığı iki farklı tipte narsisizmden söz etmektedir. Bebeğin tümgüçlü (omnipotent) konumda oldu- 
ğu birincil narsisizmde "ben" şeklinde bütünlüklü bir yapı yoktur ve otoerotik güdülerin doyurulması için beden parçalarına libidinal yatırım yapılmaktadır. Zamanla nesnelerin ve kendisini çevreleyen dünyanın farkına varan bebek, tümgüçlü konumunu koruyabilmek adına bir "ben ideali" geliştirir. Böylece birincil narsisizm evresi sonlanarak yerini ikincil narsisizme bırakır. Ben'in gelişimi ile dış dünyadan çekilen libido Ben'e yatırılır. $\mathrm{Bu}$ noktada normal gelişim sürecinde ben idealinin dışarıdaki nesnelerle özdeşim kurarak libidinal yatırımı dış nesnelere yapması beklenir. Ancak patolojik narsisizmde dışarıdaki nesnelere yatırım yapılmasını engelleyen bir mekanizma mevcuttur (Akt. Anlı, 2010; Akt. Nasio, 2018).

Freud sonraki metinlerinde Narsisizm kavramını çeşitli biçimlerden ele almış olsa da bu konuda çok detaylı çalışmaları yoktur. Freud sonrası ise çeşitli kuramcılar narsisizmi ele almışlardır. Özellikle Otto Kernberg (1928/2016) ve Heinz Kohut (1998) tarafından yürütülen çalışmalar oldukça önemlidir.

Kohut'a göre bebekler -tıpkı Freud'un belirttiği gibi- birincil narsisizm sürecinde tümgüçlü hissederler. Ancak psişik gelişim sürecinde birincil narsisizmin dengesi bozulur. Bu dengenin bozulması ile bebek ebeveynleri aracılığ 1 ile tümgüçlü konumunu korumaya çalışır." Ebeveynlerinin -önce anne ardından baba- yeterli bakımı ve kapsayıcılığı ile ileriye dönük güven ve özsaygısının temelleri atılır. Ancak bu gelişim sürecinde ciddi travmatik süreçler meydana gelirse narsisistik psikopatoloji doğacaktır (Anlı, 2010; Kohut, 1998; Taşkıntuna ve Özçürümez, 2011)

Kohut'tan sonra ise Otto Kernberg Patolojik Narsisizm kavramını ortaya atmıştır. Kernberg'in tanımlamış olduğu narsisist büyüklenmeci, kibirli, sürekli kendiden söz eden, biricik ve özel olduğunu düşünen, diğer insanlarla derin ilişkiler kurmayan ve empati yapmakta güçlük çeken kimselerdir. Bu durumun nedeni ise Kernberg'e göre çoğunlukla erken dönemlerde anne ile kurulan ilişkide hasarlanan nesne ilişkileridir. Bu kişilerin bakım verenleri genellikle soğuk ve mesafeli kişilerdir. Narsisizm ise bakım verenin soğuk ve mesafeli tutumuna karşı geliştirilen bir maskedir (Kernberg, 2016).

Narsisizmle ilgili Freud ve sonrasında çok sayıda kuramcı çeşitli teoriler geliştirmişlerdir. Çoğu ise temelde narsisizmin nedenini problemli ve hasar1 erken dönem ilişkilerine dayandırmaktadır. Bir kavram olarak kullanılan Narsisizm, DSM (Ruhsal Bozuklukların Tanısal ve İstatistiksel El Kitabı) 
içerisinde bir tanı olarak yer almıştır. İlk kez 1913 yılında Ernest Jones tarafından yayınlanan "Tanrı Kompleksi" isimli makalede Narsisistik Kişilik Bozukluğu tanımlanmıştır (McWilliams, 2017). Narsisistik Kişilik Bozukluğu ilk kez 1980 senesinde Amerikan Psikiyatri birliği tarafından DSM-III'e dahil edilmiştir. DSM'nin takip eden basımlarında da eksen II bozuklukları kategorisinde değerlendirilen Narsisistik kişilik Bozukluğu DSM-5'te değişen eksen yapısıyla boyutsal açıdan ele alınmıştır. Ancak DSM sıklıkla narsisistik kişilik bozukluğunu yalnızca büyüklenmeci kategoride değerlendirdiği için eleştirilmiştir (Eldoğan, 2016).

DSM-5 (2013)'e göre Narsisistik Kişilik Bozukluğu şu belirtiler ile karakterizedir: Özel, biricik ve eşsiz olduğu duygusu, sınırsız başarı, güç, güzellik vb. beklentilere ait düşlemler, özel muameleyi, kayırılmayı hak ettiğine inanma, empatiden yoksun olma, kendi çıkarları için başkalarını kullanma, başkalarını kıskanma gibi ilişkili çeşitli tutum ve davranışlar.

Literatür incelendiğinde ise narsisizmin temelde birbirine zıt iki boyutu olduğu görülmektedir. "Kırılgan Narsisizm" ve "Büyüklenmeci Narsisizm": Büyüklenmeci narsisizm diğer insanların tepkilerinin ve duygularının farkına varmakta güçlük çeken, kibirli ve saldırgan, büyük kitlelere hitap ediyormuş gibi konuşan ve nadiren göz teması kuran kişilerdir. Kırılgan tip ise tam aksine diğerlerinin tepkilerine oldukça duyarlı, içe dönük, utangaç, eleştiriden kaçınan kişilerdir (Gabbard, 1990).

\section{Narsisizm ve Yakın İlişkiler}

Narsisizm kavramının tarihsel gelişimi ve klinik alana yansıma biçimine bakılarak bu kişilerin diğer bireylerle kuracakları ilişkilerde kişilik örüntülerinin etkili ve önemli bir rol oynuyor olacağı düşünülmüştür. Özellikle de yetişkin yaşamında önemli bir yer kaplayan romantik ilişkilerde ve cinsellikte narsisist kişililik yapısının olumsuz yönde etkili olacağı kanaatine varılmıştır. Bu bağlamda literatür incelendiğinde konu ile ilgili çeşitli bulgulara rastlanmıştır.

Narsisist bireylerin libidinal enerjileri büyük ölçüde benlikleri etrafında yoğunlaştığı için diğer kişi ve nesnelere yönlendirilecek ilgi ve sevgi kapasiteleri sınurlı olduğu bilinmektedir (Campbell ve Foster, 2002). Narsisist bireyler erken dönem ilişkilerinde hayal kırıklığına uğrayarak incinmiş/incitilmiş kimselerdir. Bakım verenin bebeğin ihtiyaçlarını (fiziksel- 
duygusal) karşılamakta yetersiz kalması bebekte güvenilmez ve tutarsız bir dış dünya algısı yaratır. Erken dönem ilişkilerinin sonraki ilişkiler için bir prototip yaratmasından ötürü bu kişiler sonraki ilişkilerinde benzer hayal kırıklıklarını ve incinmeyi yaşamamak adına ilişkilerinde narsisizmi bir maske olacak kullanacaktır (Ozan vd., 2008).

Daha önce de belirtildiği üzere narsisist bireyler empatiden uzak, ilişkilerinde derin duygular yaşayamayan, zaman zaman agresif ve öfkeli tavırlar sergileyebilen kişilerdir. Bu durum romantik ilişkilerinde de farklı bir tonda değildir. Romantik ilişkilerinde partnerlerinden temel beklentileri onlara kendilerini iyi hissettirmeleridir. Partnerlerini idealize ederek başladıkları ilişkiler idealizasyonun azalması ya da bitmesiyle hızlıca sonlanırken yeni bir partnerle ilişkiye başlamakta güçlük çekmezler. Romantik ilişkileri genel itibari ile sıcaklık, bağllık ve yakınlıktan uzaktır (Campbell ve Foster, 2002).

Her ne kadar kibirli, öfkeli ve empatiden uzak kişiler olsalar da Kernberg (1975)'e göre bu kişilerin kötü bir sosyal yaşamları yoktur. Dış çevrenin onay ve beğenisine o kadar yoğun biçimde ihtiyaç duyarlar ki yakın ilişkilerindeki kişiye adeta "bağımlı" oldukları düşünülür. Oysa narsisist birey için bir başkasına bağlılık geliştirmek oldukça güçtür. Öteki ile kurduğu ilişki kendi ihtiyaçlarının karşılanacağı bir alandır.

Campbell ve Miller (2011) yaptıkları bir çalışmada Narsisist bireylerin çoğu zaman iyi bir sosyal statüye sahip, karizmatik ve cinsel açıdan çekici bireyler olduğunu ortaya koymuşlardır. Buradan yola çıkarak bir narsisistle ilişki yaşamayı "çikolatalı kek" metaforu ile açıklamışlardır. Biliyoruz ki çoğu zaman sağlıklı bir besinle kıyaslandığında çikolatalı kek daha caziptir. Ancak sonrasında ise alınan kaloriler ve sağlıksız içeriği pişmanlık yaratır. Campbell ve Miller (2011) da bir narsisistle ilişki yaşamanın tıpkı çikolatalı kek yemek gibi başlangiçta cazip olduğunu düşünseler de zaman içerisinde kişinin bundan pişmanlık duyacağını belirtmişlerdir.

Öte yandan literatüre nispeten yeni eklenen sapkın narsisist kavramıla bir narsisistin ilişkilerinde başlangıçta "ideal ve uygun partner" imajı yaratarak partnerini kendisine bağımlı kıldığını sonrasında çeşitli manipülatif hamleler kullanmaya başlayarak şiddeti ilişkiye dahil edeceği belirtilmiştir. Bu noktada tehlike ise partnerin bu psikolojik şiddet döngüsünden çıkmasının oldukça güç olmasıdır. Çoğunlukla narsisist bireylerin partnerlerinin tükenmesi ile bu ilişkilerde çözülme başlayacaktır (Morelli ve Couderc, 2011). 
Romantik ilişkilerin önemli bir boyutu da bilindiği üzere cinselliktir. Narsisizm düzeyi yüksek bireyler cinselliklerinde de tppkı romantik ilişkilerinde olduğu gibi yakınlık ve bağlanma ihtiyacı ihtiyacı hissetmezler. Cinsellikten temel beklentileri "fiziksel haz" ve rahatlamadır. (Foster, Shrira ve Campbell, 2006).

Winnicott (1965)'a göre erken dönemdeki ilişkisel problemlere birey "sahte kendilik" oluşturarak yanıt verir. Kendine, bedenine yabancılaşmış öznelerdir. Bu nedenle cinsellik bu kişiler için rahatlamadan ve keyif almaktan uzak bir deneyimdir. Ötekinin yabancı bedeni bu kişilerde rahatsızlık duygusu oluşturur. Bu nedenle bazı narsisist kişilerde mastürbasyon yapmak bir partnerle ilişkiye girmekten daha keyifli olabilir (Akt. Erten, 2015).

$\mathrm{Bu}$ kişilerin cinsellikte kendi ihtiyaç ve isteklerini ön plana koymaları ve cinsellik için bağlanma ve düzenli bir birliktelik aramıor oluşları onların cinselliklerinde riskli davranış eğilimi göstereceğini de düşündürmektedir. Bu düşünceden yola çıkarak yapılan bir çalışmada narsisizm seviyesi yüksek ve düşük olan kişilerin partner sayıları, kondom kullanımı gibi çeşitli risk faktörleri karşılaştırılmıştır. Narsisizm düzeyi yüksek kişiler daha fazla partnere sahip olurken öte yandan kondom kullanım oranları narsisizm seviyesi daha düşük olan kişilere oranla oldukça düşüktür. Literatürde narsisizm ile kaygı, öfke, partner sayısının fazla oluşu ve pornografik içerik kullanımı olumlu yönde ilişki göstermektedir (Martin, Benotsch, Lance ve Green, 2013; Kasper, Short ve Milam, 2014).

$\mathrm{Bu}$ aşamaya kadar literatürde narsisizm ve yakın ilişkiler etrafındaki çalışmalara dair bulgular sunulmuştur. Bu çalışmada Türkiye'deki yetişkin bireylerden elde edilecek sonuçların literatürdeki bulgular ile örtüşüp örtüşmediği incelenmek ve literatüre katkı sağlamak amaçlanmıştır. Aşağıda çalışmanın yöntemi ardından ise bulguları sunulacaktır.

\section{Yöntem}

Bu çalışmada araştırmanın değişkenleri üzerinde bir müdahale olmaksızın var olan durumun tespit edilmesini içeren "ilişkisel tarama" modeli kullanılmıştır. Narsisizm ve yakın ilişkiler üzerine bir inceleme yapmak amacyyla çeşitli değişkenler belirlenmiştir bunlar: Narsisizm, ilişki doyumu, cinsel tutumlar, riskli cinsel davranışlar ve cinsel heyecan arama olarak belirlen- 
miştir. Araştırmanın konusunu ise bu değişkenler arasındaki ilişkilerin incelenmesi oluşturmaktadır.

\section{Çalışma Grubunun Özellikleri}

Çalışmanın evreni 18 yaşın üzerindeki bireylerdir. Örneklemde özel bir kriterin olmaması nedeniyle rastgele örnekleme yöntemi tercih edilmiştir. Böylece homojen bir veri elde ederken aynı zamanda daha çok kişiye ulaşmak hedeflenmiştir.

Bu çalışmaya toplamda 350 kişi katılmıştır. Çalışmaya katılanların 209'u kadın 141'i erkektir. Katılımcıların yaş ortalaması 25,6 olarak belirlenirken maksimum katılımcı yaşı 56 minimum katılımcı yaşı ise 19 olarak bulunmuştur. Katılımcların 9'u lise, 237'si lisans, 104'ü ise lisansüstü eğitim düzeyindedir. 175 kişi ilişkisi olduğunu bildirirken 175'i ilişkisi olmadığını bildirmiştir. 159 kişi çalışmadığını bildirirken 191 kişi çalıştığını belirtmiştir. Ayrıca katılımclardan 90 kişi daha önce cinsel ilişkiye girmediğini bildirirken 260 kişi daha öncesinde bir cinsel birliktelik yaşadığını belirtmiştir.

\section{Çalışmanın Alt Amaçlan}

1. Narsisizm seviyesi cinsiyete göre farklılaşmakta mıdır?

2. Narsisizm seviyesi çalışma durumuna göre farklılaşmakta mıdır?

3. Narsisizm seviyesi ilişki durumuna göre farklılaşmakta mıdır?

4. Narsisizm seviyesi ve ilişki doyumu arasında ilişki var mıdır?

5. Örneklemde cinsel ilişkiye girmiş kişilerin cinsel tutum ve davranışları ile narsisizm düzeyleri ilişkili midir?

\section{Veri Toplama Araçları}

Bu araştırmada veri toplamak amacı ile kullanılan ölçekler Beş Faktör Narsisizm Ölçeği, İlişki Doyum Ölçeği, Cinsel tutum Ölçeği, Cinsel Risk Alma Ölçeği ve Cinsel Heyecan Arama Ölçeğidir.

Sosyodemografik Veri Formu: Sosyodemografik veri formunda katılımc1lardan yaş, cinsiyet, eğitim düzeyi, ilişki durumu ve çalışma durumu sorularına yanıt vermeleri istenmiştir. 
Beş Faktör Narsisizm Ölçeği: Beş faktör Narsisizm ölçeği Miller vd. tarafından 2012 yılında geliştirilmiştir. Türkçe uyarlaması ise Ekşi (2016) tarafından yapılmıştır. Ölçek 60 Maddeden oluşmakta ve 5'li likert tiptedir (1Kesinlikle Katılmıorum / 5- Kesinlikle Katılıyorum şeklinde puanlanmaktadır). Ölçeğin 19, 27 ve 38. maddeleri ters puanlanmaktadır. Ölçek 15 alt boyuttan oluşmaktadır. Bunlar: Onay arayıcılık, kibir, liderlik/otorite, güvensizlik, hak iddia etme, teşhircilik, sömürücülük, büyüklenme hayalleri, umursamazlık, empati eksikliği, manipülatiflik, hayranlık ihtiyacı, tepkisel öfke/öfke, utanç ve maceraperestliktir. Bu 15 alt boyutun toplanmasıyla DSM eksenindeki narsisizm puanı elde edilir. Hayranlı ihtiyacı, tepkisel öfke ve utanç alt boyutlarının toplamı kırılgan narsisizm puanı elde edilirken; diğer alt boyutların toplamı ile büyüklenmeci narsisizm puanını elde edilir.Bu çalışmanın örnekleminde narsisizm puan ortalaması 170 olarak bulunmuştur. Ölçeğin güvenilirlik katsayısı ise $(\alpha=.88)$ olarak bulunmuştur.

İlişki Doyum Ölçeği: Bu ölçek 7 maddeden oluşmakta ve 7'li likert tiptedir. Ölçek tek faktörlü bir yapıya sahiptir. Ölçekte ters puanlanan iki madde vardır. Bunlar 4. ve 7. maddelerdir. Ölçekten alınan puan artıkça ilişki doyumunun arttı̆̆ı görülmektedir. Ölçeğin güvenilirlik katsayısı $(\alpha=.86)$ olarak bulunmuştur. Ölçeğin Türkçe'ye uyarlanması Curun (2001) tarafından gerçekleşmiştir (Akt. Kılınçer ve Dost, 2013).

Bu çalışmada ise ilişki doyum puan ortalaması 27,74 olarak bulunmuştur. Ölçeğin güvenilirlik katsayısı ise $(\alpha=.68)$ olarak saptanmıştır. $(\alpha=.70)^{\prime}$ in altında olduğu için önce uç değerlere bakılmış ancak uç değerler ile güvenilirlik arasında bir bağlantı bulunamadığı için hangi maddenin güvenilirliği düşürdüğü kontrol edilmiştir. 4. Maddenin silinmesinin güvenilirlik katsayısını $(\alpha=.81)^{\prime}$ e çıkardığı tespit edilmesinin ardından bu madde çalışma dışında bırakılmıştır. Böylece güvenilirlik katsayısı $(\alpha=.81)$ olarak kabul edilmiştir.

Cinsel Tutum Ölçeği: Bu ölçek Hendrick Tarafından geliştirilmiş ve Türkçe' ye Karaçam vd. (2012) tarafından uyarlanmıştır. Toplamda 23 Madde ve 4 alt boyuttan oluşmaktadır. Ölçeğin ilk 10 maddesi onaylayıcılık (permissiveness), 11-13. Maddeleri doğum kontrolü (birth control), 14-18 aralığındaki maddeler paylaşım (communion) ve 19-23 aralığındaki maddeler araç 
olarak değerlendirme (Instrumentality) olarak belirlenmiştir. Her madde için 1-5 aralığında puanlama söz konusudur (1- Hiç katılmıyorum /5. Kesinlikle Katıliyorum). Doğum Kontrolü ve Paylaşım maddelerinin (11, 12, 13, $14,15,16,17,18)$ puanlamaları terstir. Ölçekten alınacak yüksek puanlar ideal ve dengeli bir cinselliğin emaresini oluştururken alınan düşük puanlar bireyin idealden uzaklaştı̆̆ının göstergesidir (Can, Aksoy ve Yılmaz, 2018; Hendrick, Hendrick ve Reich, 2006; Karaçam, Totan, Babür, Korkmaz ve Koyuncu, 2012).

Ölçek bireyin cinselliği nasıl algıladığına yöneliktir. "Birey cinsellikte sadece kendi ihtiyaçlarına mı odaklanıyor? Doğum kontrolü sorumluluğunu eşiyle paylaşıyor mu? Tek eşliliğe ve çok eşliliğe bakışı, cinsellik için biriyle sıcak ve samimi bir ilişki arıyor mu?" gibi çeşitli sorularla kişinin cinselliğe yönelik tutumu ölçülmektedir. Bu çalışmada bireylerin aldığı puanların ortalaması 75 puan olarak bulunmuştur. Ölçeğin güvenilirlik katsayısı ise $(\alpha=.74)$ olarak saptanmıştır.

Cinsel Risk Alma Ölçeği: Bu ölçek ilk olarak 2009 y1lında Stulhofer vd. tarafından Hırvatistan'daki genç yetişkinlerin riskli cinsel davranışlarını tanımak amacıyla kullanılmıştır. Türkçe uyarlaması ise Kıylığlu (2015) tarafından Ankara Üniversitesi Sosyal Psikoloji anabilim dalında yürütülen doktora tezi kapsamında yapılmıştır. Ölçek 10 maddeden oluşmaktadır. Soruların bir kısmı evet/hayır şeklinde cevaplamaya uygun formattadır. Ayrıca açık uçlu da iki soru mevcuttur. Bu sorulardan biri bugüne kadarki cinsel partner sayısını diğeri ise ilk cinsel birliktelik yaşını araştırmaktadır. Ölçeğin puanlaması yapılırken riskli olan davranışlar (Kondom kullanmama, yaşça büyük biriyle birlikte olma, çok sayıda partnerle eş zamanlı birliktelik gibi) ' 1 ' ötekiler sıfır olarak kodlanmıştır. Açık uçlu sorularda ise 10. Soruda 16 yaş ve öncesindeki birliktelikler riskli olarak yani ' 1 ' şeklinde kodlanmış diğerleri ' 0 ' olarak kodlanmıştır. 6 . Soruda ise katılımcların toplam partner sayıları hesaplanmış ve ortalaması ' 6 ' olarak bulunmuştur. 6'nın üzerinde olan partner sayısı riskli davranış olarak kodlanmıştır. Kıylığlu (2015) çalışmasında olduğu gibi bu çalışmada da katılımcıların \%80'inden fazlası ilişkiden önce bazen alkol kullandığını bildirdiği için yalnızca sıklıkla kullanma durumu riskli olarak kodlanmıştır. Ölçekten alınan yüksek puanlar bireyin riskli cinsel davranışlara eğiliminin olduğunu göstermektedir (Kıylığlu, 2015; Stulhofer vd., 2009). 
$\mathrm{Bu}$ çalışmada ölçekten alınan puanların ortalaması 2.15 olarak bulunmuştur. Kıylığlu'nun (2015) çalışmasında ise bu ortalama 3.31 olarak saptamıştır. Ölçekten elde edilen bulgulara göre güvenilirlik katsayısı $(\alpha=.65)$ olarak bulunmuştur. Bu sayı güvenilir kabul edilen $(\alpha=.70)$ 'in altında olduğu için önce uç değerlere bakılmış ancak uç değerler ile güvenilirlik arasında bir bağlantı bulunamadığı için hangi maddenin güvenilirliği düşürdüğü kontrol edilmiştir. Ölçeğin 7. Maddesi çalışmanın dışında bırakılmış böylece güvenilirlik katsayısı $(\alpha=.71)$ olarak bulunmuştur. Ölçeğin orijinalinde bu katsayı $(\alpha=65)$, Kıylığlu'nun (2015) çalışmasında ise $(\alpha=.71)$ olarak bulunmuştur.

Cinsel Heyecan Arama Ölçeği: Kalichman vd. (1994) tarafından geliştirilen Cinsel Heyecan Arama Ölçeği Kıylığlu (2012) tarafından Türkçe' ye uyarlanmıştır. Yapılan çalışmada orijinalinde olan 1 madde çıkarılmış ve 10 maddelik bir ölçek haline getirilmiştir. Ölçeğin güvenilirlik katsayısı $(\alpha=.84)$ olarak bulunmuştur. Ölçek 4'lü likert tiptedir (1- Hiç katılmıyorum ve 4Bütünüyle katılıyorum). Ölçekten alınan puanlar yükseldikçe heyecan arayışının da yükseldiği görülmektedir (Kıylıoğlu, 2013).Bu çalışmada ise heyecan arama toplam puanın ortalaması 21.22 güvenilirlik katsayısı ise $(\alpha=$ .88) olarak bulunmuştur.

\section{Verilerin Toplanması}

Bu çalışmada örneklemin evreni temsil gücünü arttırmak adına olabildiğince çok sayıda kişiye ulaşmak hedeflenmiştir. Bu nedenle çalışma formları hem online hem de manuel olarak uygulanmıştır. Ancak formların bireyin mahrem alanıyla ilişkili sorular içermesi nedeniyle elde edilecek yantların güvenilirliğinin düşük olacağı sınıflarda gerçekleştirilen pilot uygulamayla saptanmıştır. Bu nedenle çalışmaya yalızca online formlardan elde edilen yanitlar dahil edilmiştir.

Çalışmada bireylere ait hiçbir kişisel bilgi istenmemiştir. Bunun yanı sıra çalışma hakkında kısaca bir bilginin verildiği ve çalışmaya katılımdan diledikleri anda geri çekilebileceklerini ifade eden bir gönüllü onam formu sunulmuştur. 


\section{Verilerin Analizi}

Anketlerden elde edilen veriler ilk aşamada SPSS 22 paket programı üzerinde düzenlenmiş ardından veri setinin dağılımının normalliği test edilmiştir. Sonraki aşamada ise araştırmanın amaç ve sorularına uygun biçimde analizler yapılmıştır.

Elde edilen sonuçlar bulgular kısmında ifade edilmiştir.

\section{Bulgular}

Veri analizine geçmeden çalışmanın ilk aşamasında veri dağılımının normalliği test edilmiştir. Normalliği test etmek için çarpıklık ve basıklık katsayıları kontrol edilmiştir. Çarpıklık ve basıklık katsayılarının normal dağılım için sahip olması gereken aralıkla ilgili çeşitli çalışmalar olsa da literatürde en sık atıf yapılan çalışma Tabachnick ve Fidell (2013) tarafından belirtilen $+1,5 /-1,5$ aralığıdır.

Tablo 1. Ölçeklerin Çarpıklık ve Basıklık Katsayıları

\begin{tabular}{lll}
\hline Değişkenler & Skewness (Çarpıklık) & Kurtois (Basıklık) \\
\hline Kırılgan Narsisizim &,- 055 &,- 333 \\
BüyüklenmeciNarsisizim &, 314 &,- 046 \\
Narsisizm Toplam &, 249 &,- 155 \\
Cinsel Heyecan Arama &, 430 & -512 \\
Cinsel Risk Alma & 1,32 & 1,29 \\
Cinsel Tutum &, 296 &,- 141 \\
Ilişki Doyumu &,- 942 &, 446 \\
\hline
\end{tabular}

Tabloya bakıldığında her değişkenin çarpıklık ve basıklık değerlerinin $+1,5 /-1,5$ aralığında olduğu görülmektedir. Verilerin normal dağıldığı varsayımından yola çıkarak araştırma sorularının çözümlenmesinde parametrik analizler tercih edilmiştir.

Bulgular incelendiğinde kırılgan narsisizm $\left(t_{(348)}=-1,09 ; p>05\right)$ düzeyinde cinsiyete göre istatistiksel olarak anlamlı bir farklılık bulunmamıştır. Ancak büyüklenmeci narsisizm $\left(\mathrm{t}_{(348)}=4,19 ; \mathrm{p}<.01\right)$ ve narsisizm toplam puanında $\left(t_{(348)}=3,43 ; p<.01\right)$ cinsiyete göre istatistiksel olarak anlamlı bir farklılık olduğu görülmektedir. Sonuçlara göre erkeklerin narsisizm (Ort.= 175,5) ve büyüklenmeci narsisizm puanları (Ort.= 140,7) kadınların puanlarından daha yüksektir. 


\section{Araştırma Sorularnnı Çözümlenmesi}

Tablo 2. Narsisizm Düzeyi ve Cinsiyet

\begin{tabular}{llcccccc}
\hline Değişken & Cinsiyet & $\mathbf{N}$ & $\overline{\boldsymbol{x}}$ & SS & SD & $\mathbf{t}$ & $\mathbf{p}$ \\
\hline Kurılgan Narsisizm & Kadın & 209 & 35.60 & 7.16 & 348 & $-1,09$ &, 273 \\
& Erkek & 141 & 34,78 & 6,36 & & & \\
\hline Büyüklenmeci Narsisizm & Kadın & 209 & 131,3 & 20,58 & 348 & 4,19 &, $000^{* *}$ \\
& Erkek & 141 & 140,7 & 20,59 & & & \\
\hline Narsisizm Toplam & Kadın & 209 & 166,9 & 23,3 & 348 & 3,43 &, $001^{* *}$ \\
& Erkek & 141 & 175,5 & 23,3 & & & \\
\hline
\end{tabular}

Tablo 3. Narsisizm Düzeyi İlişki Durumu

\begin{tabular}{llcccccc}
\hline Değişken & Cinsiyet & $\mathbf{N}$ & $\overline{\boldsymbol{x}}$ & $\mathbf{S S}$ & SD & $\mathbf{t}$ & $\mathbf{p}$ \\
\hline Kurılgan Narsisizm & İişkisi yok & 175 & 34,89 & 7.36 & 340,06 & $-1,037$ &, 301 \\
& İişkisi var & 175 & 35,67 & 6,31 & & &, $018^{*}$ \\
\hline Büyüklenmeci Narsisizm & İişkisi yok & 175 & 132,5 & 21,56 & 348 & $-2,37$ &, $015^{*}$ \\
& İlişkisi var & 175 & 137,8 & 20,27 & & & \\
\hline Narsisizm Toplam & İişkisi yok & 175 & 167,4 & 23,9 & 348 & $-6,06$ &, \\
& İlişkisi var & 175 & 173,4 & 22,2 & & & \\
\hline
\end{tabular}

Bulgular incelendiğinde kırılgan narsisizm $\left(\mathrm{t}_{(340,06)}=-1,037 ; \mathrm{p}>.05\right)$ olarak bulunmuştur. Bu sonuca göre ilişki durumunun kırılgan narsisizm üzerinde istatistiksel olarak anlamlı bir farklılık yaratmadığı görülmektedir. Büyüklenmeci narsisizm $\left(t_{(348)}=-2,37 ; p<.05\right)$, narsisizm toplam $\left(t_{(348)}=-6,06 ; p<.05\right)$ puanlarının ise ilişki durumuna göre istatistiksel olarak anlamlı biçimde farklılaştığı görülmüştür. İlişkisi olan kişilerin büyüklenmeci narsisizm puanları (Ort.=137,8) ve narsisizm toplam puanları (Ort.=173,4) ilişkisi olmayan kişilere göre daha yüksek bulunmuştur.

Tablo 3. Narsisizm Düzeyi Çalışma Durumu

\begin{tabular}{|c|c|c|c|c|c|c|c|}
\hline Değişken & Cinsiyet & $\mathbf{N}$ & $\overline{\bar{x}}$ & SS & SD & $T$ & $p$ \\
\hline Kurlgan & Çalışmıyor & 159 & 35,09 & 6,78 & 348 &,- 455 & 650 \\
\hline Narsisizm & Çalışıyor & 191 & 35,42 & 6,93 & & & \\
\hline \multirow[t]{2}{*}{ Büyüklenmeci Narsisizm } & Çalışmiyor & 159 & 134,63 & 19,90 & 348 &,- 439 & 661 \\
\hline & Çalışıyor & 191 & 135,62 & 21,97 & & & \\
\hline Narsisizm & Çalışmıyor & 159 & 169,7 & 23,9 & 348 &,- 531 &, 596 \\
\hline Toplam & Çalışıyor & 191 & 171,05 & 22,2 & & & \\
\hline
\end{tabular}

Bulgular incelendiğinde kırılgan narsisizm ( $\mathrm{t}(348)=-0,455 ; \mathrm{p}>.05)$ büyüklenmeci narsisizm $\left(\mathrm{t}_{(348)}=-0,439 ; \mathrm{p}>.05\right)$, narsisizm toplam $\left(\mathrm{t}_{(348)}=-0,531 ; \mathrm{p}>.05\right)$ puanlarında çalışma durumuna göre istatistiksel olarak anlamlı bir farklılık bulunamamıştır. 
Tablo 4. Narsisizm ve İlişki Doyumu değişkenlerinin İlişkisi

\begin{tabular}{lllll}
\hline & $\begin{array}{l}\text { Kurlgan } \\
\text { Narsisizm }\end{array}$ & $\begin{array}{l}\text { Büyüklenmeci } \\
\text { Narsisizm }\end{array}$ & $\begin{array}{l}\text { Narsisizm } \\
\text { Toplam }\end{array}$ & $\begin{array}{l}\text { Ilişki } \\
\text { Doyumu }\end{array}$ \\
\hline $\begin{array}{l}\text { Kurlgan } \\
\text { Narsisizm }\end{array}$ & 1 & & & \\
\hline $\begin{array}{l}\text { Büyüklenmeci } \\
\text { Narsisizm }\end{array}$ &, $178^{* *}$ & 1 & 1 & \\
\hline $\begin{array}{l}\text { Narsisizm } \\
\text { Toplam }\end{array}$ &, $455^{* *}$ &, $957^{* *}$ &,$- 107^{*}$ & 1 \\
\hline $\begin{array}{l}\text { Iliş̧i } \\
\text { Doyumu }\end{array}$ &,- 097 &,- 087 & & \\
\hline
\end{tabular}

Çalışmanın bu kısmında tüm örneklem dahil edildiği bir korelasyon analizi yapılmıştır. Narsisizm toplam puanı ile ilişki doyumu $(r=-0,107, p<.05)$ arasında olumsuz yönde anlamlı bir ilişki bulunmuştur.

Tablo 5. Cinsel İlişkiye Girmiş Kişilerin Narsisizm, İlişki Doyumu ile Cinsel Tutum ve Davranışlarının İlişkisi

\begin{tabular}{|c|c|c|c|c|c|c|c|}
\hline & $\begin{array}{l}\text { Kırlgan } \\
\text { Narsisizm }\end{array}$ & $\begin{array}{l}\text { Büyüklenmeci } \\
\text { Narsisizm }\end{array}$ & $\begin{array}{l}\text { Narsisizm } \\
\text { Toplam }\end{array}$ & $\begin{array}{l}\text { İlişki } \\
\text { Doyumu }\end{array}$ & $\begin{array}{l}\text { Cinsel } \\
\text { Risk }\end{array}$ & $\begin{array}{l}\text { Heyecan } \\
\text { Toplam }\end{array}$ & $\begin{array}{l}\text { Cinsel } \\
\text { Tutum }\end{array}$ \\
\hline $\begin{array}{l}\text { Kırılgan } \\
\text { Narsisizm }\end{array}$ & 1 & & & & & & \\
\hline $\begin{array}{l}\text { Büyüklenmeci } \\
\text { Narsisizm }\end{array}$ & $211^{* *}$ & 1 & & & & & \\
\hline $\begin{array}{l}\text { Narsisizm } \\
\text { Toplam }\end{array}$ & $470^{* *}$ &, $962^{* *}$ & 1 & & & & \\
\hline $\begin{array}{l}\text { İlişki } \\
\text { Doyumu }\end{array}$ &,- 038 & $-137^{*}$ &,$- 134^{*}$ & 1 & & & \\
\hline $\begin{array}{l}\text { Cinsel Risk } \\
\text { Toplam }\end{array}$ & ,092 &, $382^{* *}$ &, $370^{* *}$ &,$- 210^{* *}$ & 1 & & \\
\hline $\begin{array}{l}\text { Cinsel } \\
\text { Heyecan } \\
\text { Arama }\end{array}$ & $249^{* *}$ & $459^{* *}$ & $484^{* *}$ &,$- 166^{* *}$ &, $542^{* *}$ & 1 & \\
\hline $\begin{array}{l}\text { Cinsel } \\
\text { Tutum }\end{array}$ &,$- 142^{*}$ &,$- 337^{* *}$ &,$- 334^{* *}$ &, $229^{* *}$ &,$- 455^{* *}$ & $-544^{* *}$ & 1 \\
\hline
\end{tabular}

Çalışmanın bu kısmında yalnızca cinsel ilişkiye girmiş kişilerin dahil edildiği bir korelasyon analizi yapılmıştır. Bulgular şu yöndedir:

Kırılgan narsisizm ile narsisizm toplam puanı ( $\mathrm{r}=0,470, \mathrm{p}<.01)$, cinsel heyecan arama $(\mathrm{r}=0,249, \mathrm{p}<.01)$, büyüklenmeci narsisizm $(\mathrm{r}=0,211, \mathrm{p}<.01)$ arasında olumlu yönde anlamlı bir ilişki bulunurken; cinsel tutum ( $r=-0,142$, $\mathrm{p}<.05)$ ile olumsuz yönde anlamlı bir ilişki bulunmuştur.

Büyüklenmeci narsisizm ile narsisizm toplam ( $\mathrm{r}=0,962, \mathrm{p}<.01)$, cinsel heyecan arama $(r=0,459, \mathrm{p}<.01)$ ve cinsel risk $(\mathrm{r}=0,382, \mathrm{p}<.01)$ değişkenleri arasında olumlu yönde ve anlamlı bir ilişki bulunurken; İlişki doyumu (r=- 
$0,137, \mathrm{p}<.05)$ ve cinsel tutum $(\mathrm{r}=-0,337, \mathrm{p}<.01)$ değişkenleri arasında olumsuz yönde anlamlı bir ilişki bulunmuştur.

Narsisizm toplam puanı ile cinsel heyecan arama $(\mathrm{r}=0,484, \mathrm{p}<.01)$ cinsel risk $(\mathrm{r}=0,370, \mathrm{p}<.01)$ olumlu yönde anlamlı bir ilişki bulunurken; İlişki doyumu $(\mathrm{r}=-0,134, \mathrm{p}<.05)$ ve cinsel tutum $(\mathrm{r}=-0,334$, $\mathrm{p}<.01)$ değişkenleri arasında olumsuz yönde anlamlı bir ilişki bulunmuştur.

İlişki doyumu ile cinsel tutum $(\mathrm{r}=0,229, \mathrm{p}<.01)$ arasında olumlu yönde ve anlamlı bir ilişki bulunurken; cinsel heyecan arama $(\mathrm{r}=0,166, \mathrm{p}<.01)$ ve cinsel risk $(r=-0,210, p<.01)$ değişkenleri arasında olumsuz yönde anlamlı bir ilişki bulunmuştur.

\section{Tartışma ve Sonuç}

Bu çalışmanın ilk aşamasında narsisizm düzeyi ve sosyodemografik değişkenler incelenmiştir. Elde edilen bulgulara göre kadınların ve erkeklerin kırılgan narsisizm puanları cinsiyete göre farklılık göstermezken; erkeklerin büyüklenmeci narsisizm ve narsisizm puanları kadınlara göre daha yüksek bulunmuştur. Konu ile ilgili literatüre bakıldığında erkeklerin narsisizm puanlarının kadınlara göre daha yüksek bulunduğu çeşitli çalışmalar bulunmaktadır (Golomb, Fava, Abraham ve Rosenbaum, 1995: Foster, Campbell ve Twenge, 2013: Tschanz, Morf ve Turner, 1998). Ancak aksi yönde sonuçların olduğu çalışmalar da mevcuttur. Örneğin Grijalva vd. (2014) yılında yapmış oldukları bir meta-analiz çalışmasında cinsiyet ve narsisizm ile ilgili çok sayıda çalışmayı inceleyerek bu konu ile ilgili cinsiyet açısından net bir üstünlüğün olmadığı sonucuna varmışlardır. Bu çalışmada da saptandığ 1 üzere erkeklerin narsisizm seviyesinin daha yüksek oluşu toplumsal cinsiyet rolleri ile ilintili olabilir. Bir erkeğin narsisizme ait öfke, saldırganlık, empati eksikliği gibi duygu ve davranışlarını yansıtması toplum tarafından daha kabul edilebilirdir. Bu durumun yetiştirme biçimleri üzerinde de etki ederek erkeklerin daha fazla büyüklenmeci narsisizm özellikleri göstermesine yol açıyor olması muhtemeldir. Bir diğer sosyodemografik değişken olan ilişki durumu ve narsisizm ile ilgili bulgu ise romantik bir ilişkisi olmayan kişilerin narsisizm seviyesi daha düşük bulunmuştur. Bu literatürdeki bulgulardan yola çıkarak narsisizm seviyesi yüksek kişilerin kendi konfor alanlarını koruyabilmek adına daha sık romantik ilişki içerisine girdikleri 
şeklinde yorumlanabilir. Çalışma durumu ve narsisizm arasında bir farklılaşma bulunmazken literatürde de benzer bir sonuca rastlanmamıştır.

$\mathrm{Bu}$ çalışmanın sonraki aşamasında ise temel değişkenler ve narsisizm ilişkisi incelenmiştir. Elde edilen bulgulara göre narsisizm toplam puanı ile ilişki doyumu arasında anlamlı ancak zayıf düzeyde bir ilişki bulunmuştur. Bu iki değişken arasında zayıf düzeyde bir ilişki olmasının en önemli sebeplerinden biri çalışmaya katılan örneklemin görece "sağlıklı" olmasından kaynaklıdır. Çalışmaya katılan kişilerin narsisizm düzeyleri patolojik seviyede değildir. Ancak elde edilen sonucun anlamlı olması narsisizm düzeyi arttıkça ilişki doyumunun düştüğünün göstergesidir.

Literatür incelendiğinde Foster vd. (2006) yapmış oldukları çalışmada bu çalışmada elde edilen sonuca benzer biçimde narsisizm seviyesi yükseldikçe ilişki doyumunun düştüğünü tespit etmişlerdir. Giriş kısmında ifade edildiği üzere narsisist bireyler ikili ilişkilerini kendi istek ve ihtiyaçları üzerine şekillendirirler. Partnerlerinin fiziksel ve duygusal ihtiyaçlarını göz ardı ederken eş duyum becerilerinin de düşük olduğu bilinmektedir (Campbell ve Foster, 2002: Campbell ve Miller, 2011). Bu noktada kişilerin doyumlarının partnerlerinin onların ihtiyaçlarını karşılama becerisi ile ilişkili olduğu düşünülebilir. Ancak bu kişiler için zamanla partnerleri yetersiz ve eksik kalacağından doyumlarının düşük olması da beklenen bir sonuçtur.

Smolewska ve Dion (2005) tarafından yapılan bir çalışma narsisistlerin güvensiz bağlanma biçimine sahip olduğunu ortaya koymuştur. İlişkiler üzerinde etkisi tartışılmaz olan bağlanma biçiminin, narsisist bireylerin ilişki doyumları üzerinde de etkili olduğu düşünülebilir. Literatürde bu konu ile ilgili nicel veriler oldukça kısıtlı olsa da narsisistlerin klinik düzeyde çizmiş oldukları profile bakarak ilişkileri ve ilişki doyumları üzerine çeşitli çıkarımlar yapmak olasidir.

Cinsellik ve narsisizm'e ait bulgularda ise narsisizmin kırlgan boyutu ile heyecan arama ve cinsel tutum ilişkili çıkarken riskli cinselliğin bir ilişkisi bulunmamıştır. Büyüklenmeci narsisizmin ise heyecan arama ve cinsel tutuma ek olarak riskli cinsel davranışlar ile ilişkili olduğu saptanmıştır. Konu ile ilgili yapılan çalışmaların sayısı oldukça kısıtlı olsa da benzer çalışmalardan elde edilen bulgular şu şekildedir: Webster ve Brian (2006) çalışmalarında sosyoseksüalite, yani bağ kurmaksızın girilen cinsel ilişkiler ve cinsel tutumların narsisizm ile ilişkili olduğunu bulmuşlardır. Wryobeck ve Wiederman (1999) yaptıkları bir çalışmada narsisistik cinsel davranışlar göste- 
ren kişilerin cinsel heyecan arama ve cinsel risk davranışlarının (ör. çok sayıda partner gibi) daha fazla olduğunu belirtmişlerdir. HIV tanısı almış 303 kişi ile yürütülen başka bir çalışmada ise bireylerin narsisizm düzeyleri arttıkça cinsellik öncesinde alkol kullanımının arttı̆̆ bunun da riskli cinsel davranışar ile ilişkili olduğunu ifade edilmiştir (Martin vd., 2013).

Bu çalışmadan elde edilen bulgular, literatürde sınırlı sayıda olan çalışmalar ile büyük ölçüde uyumludur. Narsisist bireylerin ilişkisel anlamda genel tutumları düşünüldügünde bulgular beklendiği yönde çıkmıştır. K1rılgan narsisizmde risk davranışı görülmemesine karşın cinsel heyecan arama davranışının görülmesi bu örüntüde görülen yoğun "utanç" ile ilişkili olduğu düşünülebilir. Yani bu kişiler cinsellikle ilgili düşünce boyutunda riskli davranışlara daha eğilimliyken, eyleme geçme konusunda çekimser kalabilirler. Büyüklenmeci narsisizm söz konusu olduğunda ise bu kişilerin sürekli olarak her şeyi hak ettiği duygusu içinde olmaları ve büyüklenmeci tutumları nedeni ile kendilerine bir zarar gelmeyeceği düşüncesine kapılarak cinselliklerinde daha riskli bir tarz benimsiyor olmaları muhtemeldir.

Çalışmadan elde edilen sonuçlar literatürde kısıtlı olan bulgular ve narsisizmin genel tanı kriterleri ile örtüşmektedir. Sonuç olarak narsisizmin romantik ilişkilerde ve romantik ilişkilerin önemli bir alanı olan cinsellik üzerinde olumsuz yönde etkisi olduğu görülmüştür.

\section{Sinırlılıklar ve Öneriler}

Bu çalışma yüksek lisans tezinden üretilmiş olması nedeniyle veri toplama süreci daha kısıtlı bir zamanda gerçekleşmek durumunda kalmıştır. Örneklem sayısının yüksek olmayışı çalışmanın en temel sınırlılığını oluşturmaktadır. Bir diğer sınırlılık ise konu ile ilgili literatürde sınırlı sayıda çalı̧̧ma bulunmasıdır. Bu durum elde edilen verilen literatürle kıyaslanmasını zorlaştırmıştır.

Bu konu ve ilişkili konular ilgili sonraki çalışmalarda yapılması gereken en temel öneri örneklem sayısının arttırılmasıdır. Çalışmanın araştırma kısmında sosyodemografik verilerin daha detaylı ele alınması, ilişkiler ve cinsellikle ilgili başka değişkenlerin de (örn. Bağlanma vb.) araştırmaya dahil edilmesinin ise hem literatüre hem de klinik alana katkı sağlayacağı düşünülmektedir. 


\title{
EXTENDED ABSTRACT
}

\section{Narcissism, Close Relationships and Sexuality in Adult Individuals}

\author{
$*$ \\ Berhu Erdoğan - Muzaffer Şahin \\ Nişantaşı University, İstanbul Arel University
}

Research Purpose:In this study, the role of narcissism in close relationships was examined. The main purpose of the study was to determine the effect of narcissism on various parameters of the relationships. These parameters were determined as relationship satisfaction and sexual attitudes and behaviours. At the same time, it is aimed that the findings to be obtained will be guiding in the clinical studies.

Literature Review: In the introduction part of the study, a general conceptual framework on narcissism is presented. Born from a mythological myth, this concept has become a psychiatric diagnosis in the historical process. This diagnosis, characterized by intense self-esteem, is also associated with lack of empathy, selfishness and exploitative behaviour. Studies on close relationships and narcissism revealed that narcissistic individuals are the ones who emphasize their own desires and needs and do not establish intimacy and commitment. However, despite all these negative aspects, they do not have a bad social life. Attitudes and behaviours are initially attractive and charismatic by their partners. However, it is another result that the partners in the relationship will show signs of extinction over time.

Methodology: in this study, "relational screening model" was used to determine the present situation without interfering on the variables of the study. The sample of the study consisted of 350 participants selected by random sampling method. Sociodemographic Data Form, Five Factor Narcissism Scale, Relationship Satisfaction Scale, Sexual Risk Taking Scale, Sexual Attitude Scale and Sexual Excitement Seeking Scales were applied to these individuals. 
After the data collection process, the data were analysed by SPSS 22 package program. Before the analysis of the research questions, the normality of the data distribution was examined. The normality was checked using the skewness and kurtosis coefficients. After the normal distribution of the data, parametric tests ( $t$ test and pearson correlation) were used for the analysis of the questions.

Findings: The findings of the study were as follows: There was a significant relationship between narcissism and relationship satisfaction, albeit at a low level. This result can be interpreted as the relationship satisfaction decreases as the level of narcissism increases or the relationship satisfaction increases as the level of narcissism decreases.

When the findings on narcissism and sexuality are examined, it is seen that grandiose narcissism is associated with sexual risk, seeking sexual excitement and sexual attitudes. According to these results, it is seen that individuals with high grandiose narcissism exhibit sexually risky behaviours, seeking excitement in their sexuality and at the same time have lower healthy attitudes towards sexuality. At this point, the only point that separates fragile narcissism and grandiose narcissism is that fragile narcissism does not correlate with sexual risk behaviours.

Conclusion and Results: According to the results of the data analysis of this study, a significant but not strong relationship was found between narcissism and relationship satisfaction, sexual attitudes and behaviours. One of the most important reasons for the weak relationship between these two variables is that the sample was relatively healthy. Narcissism levels of the participants were not pathological. However, the fact that the result obtained is significant is an indication that the relationship satisfaction decreases as the level of narcissism increases.

The findings of this study are largely consistent with the limited number of studies in the literature. Considering the general relational attitudes of narcissistic individuals, the findings are in the expected direction. Although there is no risk behaviour in fragile narcissism, sexual excitement seeking behaviour may be related to the intense shame seen in this pattern. In other words, while they are more prone to risky behaviours in the dimension of sexual thinking, they may abstain from taking action. When 
it comes to grandiose narcissism, it is possible that these people will always feel that they deserve everything and that they will adopt a very risky style in their sexuality by thinking that they will not harm them because of their grandiose attitude..

\section{Kaynakça / References}

Amerikan Psikiyatri Birliği (2013). Mental bozuklukların tanısal ve sayımsal el kitabı, Beşinci Baskı (DSM-5). E Köroğlu (Çev. Ed.). Ankara: Hekimler Yayın Birliği.

Anl, İ. (2010). Psikanalizde narsisizm. İstanbul: Nobel Tip Kitabevleri.

Campbell, W. K., ve Foster, C. A. (2002). Narcissism and commitment in romantic relationships: An investment model analysis. Personality and Social Psychology Bulletin, 28(4), 484-495.

Campbell, W. K., ve Miller, J. D. (2011). The handbook of narcissism and narcissistic personality disorder. Hoboken, New Jersey: John Wiley and Sons Inc.

Can,R., Aksoy, E. Y., Yılmaz, D. S. (2018).Ebelik Bölümü Öğrencilerinin Cinsel Tutum ve Öz-Bilinç Durumlarının Değerlendirilmesi. Journal of Human Sciences, 15 (2), 1338-1347.

Eldoğan, D. (2016). Hangi narsizm? büyüklenmeci ve kırılgan narsizmin karş1laştırılmasına ilişkin bir gözden geçirme. Türk Psikoloji Yazıları,19(37), 110.

Erten,Y. (2015, Aralı). Tek kişilik balo: Narsisizm üzerine kuramsal ve klinik notlar. Yansitma Dergisi, 24, 11-32.

Foster, J. D., Campbell, W. K. ve Twenge, J. M. (2003). Individual differences in narcissism: Inflated self-views across the lifespan and around the world,. Journal of Research in Personality, 37(6), 469- 486. doi:10.1016/s0092-6566(03)00026-6

Foster, J. D., Shrira, I., ve Campbell, W. K. (2006). Theoretical models of narcissism, sexuality and relationship commitment. Journal of social and Personál Relationships, 23 (3), 367-386.

Gabbard, G. O. (1989). Two subtypes of narcissistic personality disorder. Bulletin of the Menninger Clinic,53(6), 527-532.

Golomb, M., Fava, M., Abraham, M., ve Rosenbaum, J. F. (1995). Gender differences in personality disorders. The American Journal of Psychiatry, 152(4), 579-582. 
Grijalva, E., Newman, D. A., Tay, L., Donnellan, M. B., Harms, P. D., Robins, R. W. ve Yan, T. (2015). Gender differences in narcissism: A meta-analytic review. Psychological bulletin, 141(2), 261-310.

Hendrick, C., Hendrick, S.S. ve Reich, D.A. (2006). The brief sexual attitudes scale. Journal of Sex Research, 43 (1),76-86.

Karaçam, Ö., Totan, T., Babür, Korkmaz, Y., ve Koyuncu, M. (2012). Hendrick cinsel tutum ölçeği kısa formunun Türkçeye Uyarlanması, geçerlilik ve güvenilirlik çalışması. Anadolu Psikiyatri Dergisi, 13 (2), 138-144.

Kasper, T. E., Short, M. B., ve Milam, A. C. (2014). Narcissism and internet pornography use. Journal of Sex and Marital Therapy, 41(5), 481-486.

Kernberg, O. (2016). Sinır durumlar ve patolojik narsisizm. 4. Baskı. M. Atakay (Çev.), İstanbul: Metis Yayınları (Orijinal eserin yayın tarihi 1975).

Kılınçer, S. A., Dost, T. M. (2013). Romantik ilişkiyi değerlendirme ölçeğinin değerlendirilmesi. Eğitimde ve Psikolojide Ölçme ve Değerlendirme Dergisi, $4(1), 15-32$.

Kıylıoğlu, L. (2013). Cinsel heyecan arama ölçeği (Chaö): Türkçeye uyarlama, geçerlik ve güvenirlik çalışması. Ankara Sağllk Bilimleri Dergisi, 2(1-2-3), 41-54.

Kıylıŏlu, L. (2015). Karşıt cinsel erkek üniversite öğrencilerinde riskli cinsel davranış. Doktora Tezi.Ankara: Ankara Üniversitesi SBE.

Kızltan, H.(2004). Narsisizm ve psikopatolojisi. http://www.psikomitoloji.com (18.08.2013).

Kohut, H.(1998). Kendiliğin çözümlenmesi: Narsisitik kişilik bozukluklarının psikanalitik tedavisine sistemli bir yaklaşım. S. M. Tura (Çev.), İstanbul: Metis Yayınları. (Orijinal eserin yayın tarihi 1971).

Martin, A. M., Benotsch, E. G., Lance, S. P., ve Green, M. (2013). Transmission risk behaviors in a subset of hiv-positive individuals: The role of narcissistic personality features. Personality and Individual Differences, 54(2), 256-260.

McWilliams, N. (2017). Psikanalitik tanı. 6. Baskı. E, Kalem (Çev.), İstanbul: Bilgi Üniversitesi Yayınları.

Morelli, P.C. ve Couderc, P. (2011). İkili ilişkilerde duygusal manipülasyon narsisist bir partnerle yüzleşmek. I. Ergüden (çev.), İstanbul: İletişim Yayınları.

Nasio, J.D. (2018). Psikanalizin yedi temel kavramı. 2. Baskı. Ö. Erşen ve M.Erşen (çev.), Ankara: İmge Kitapevi. 
Ozan, E., Kırkpınar, İ., Aydın, N., Fidan, T. ve Oral, M. (2008). Narsistik kişilik bozukluğu gelişim süreçleri ve yaşamı. Psikiyatride Derlemeler, Olgular ve Varsayımlar Dergisi, 2(1), 25-32.

Pulver, S. E. (1970). Narcissism: The term and the concept. Journal of the American Psychoanalytic Association, 18(2), 319-341.

Smolewska, K. ve Dion, K. (2005). Narcissism and adult attachment: A multivariate approach. Self and Identity, 4(1), 59-68.

Štulhofer, A., Graham, C., Božičević, I., Kufrin, K., ve Ajduković, D. (2009). An assessment of hiv/stı vulnerability and related sexual risk-taking in a nationally representative sample of young Croatian adults. Archives of Sexual Behavior, 38(2), 209-225.

Tabachnick, B. G. ve Fidell, L. S. (2013). Using multivariate statistic. 6. Edition. Boston: Pearson.

Taşkıntuna, N. ve Özçürümez, G. (2011). Mükemmeli ararken: Bir iç dünya araştırması. Klinik Psikiyatri Dergisi, 14(2), 103-114.

Terbaş, Ö. (2004).Kendilik psikolojisi kuramina göre kendilik bozuklukları: Bir olgu sunumu. Türkiye Psikiyatri Dergisi, 15(1),70-76.

Tschanz, B. T., Morf, C. C., ve Turner, C. W. (1998). Gender differences in the structure of narcissism: A multi-sample analysis of the narcissistic personality inventory. Sex Roles, 38(9-10), 863-870.

Webster, G. D. ve Bryan, A. (2007). Sociosexual attitudes and behaviors: Why two factors are better than one. Journal of Research in Personality, 41(4), 917-922.

Wryobeck, J. M. ve Wiederman, M. W. (1999). Sexual narcissism: Measurement and correlates among college men. Journal of Sex $\mathcal{E}$ Marital Therapy, 25(4), 321-331.

\section{Kaynakça Bilgisi / Citation Information}

Erdoğan, B. ve Şahin, M.(2020). Yetişkin bireylerde narsisizm, yakın ilişkiler ve cinsellik. OPUS-Uluslararası Toplum Araştırmaları Dergisi, 16(27), 266-287. DOI: 10.26466/opus.671715 